EDITORIAL ARTICLE

\title{
Amantadine Might be Used as a Drug for SARS-Cov-2 Treatment?
}

\author{
Zeynep Gunes Ozunal ${ }^{1}$ and Sevki Sahin ${ }^{2, *}$
}

${ }^{1}$ Medical Pharmacology Department, Faculty of Medicine, Maltepe University, Istanbul, Turkey; ${ }^{2}$ Neurology Department, Faculty of Medicine, Maltepe University, İstanbul, Turkey

A R T I C L E H IS T O R Y

Received: April 14, 2020

Revised: June 18, 2020

Accepted: June 19, 2020

DOI:

$10.2174 / 2666796701999200713192912$
Abstract: Coronavirus Disease 2019 (COVID-19) infection, the pandemics, caused by severe acute respiratory syndrome coronavirus 2 (SARS-CoV-2) has no known effective radical pharmacotherapy and just supportive approach at present. Amantadine is a drug used in Parkinson's disease and other parkinsonisms; and is known to increase indirectly dopamine by antagonistic effects at the N-methyl-Daspartate (NMDA) receptor by increasing the release and blocking the reuptake of dopamine. Initially, amantadine was approved as an antiviral drug. We hypothesize that if amantadine is considered its antiviral, immunological and neurostimulant effects might be useful in the supportive treatment of SARSCoV-2 cases, especially those who developed acute respiratory failure with decreased vigilance and are being monitored in the intensive care unit. Further phase III clinical trials are needed.

Keywords: Amantadine, pharmacology, neurology, SARS-CoV-2, drug repositioning.

\section{INTRODUCTION}

Coronavirus Disease 2019 (COVID-19) infection, the pandemics, caused by severe acute respiratory syndrome coronavirus 2 (SARS-CoV-2) has no known effective radical pharmacotherapy and just supportive approach at present. Dopamine is an important neurotransmitter that regulates critical functions in the central nervous system (CNS). Growing research has also shown that dopamine acts as an important regulator of immune functions [1]. A dopaminergic drug amantadine has positive effects on the immune system, acting on dopamine production in T cells [2].

Amantadine is a drug used in idiopathic Parkinson's disease and other parkinsonisms, whose symptoms include resting tremor, rigidity, and bradykinesia [3]. Its mechanism of action includes an indirect increase in dopamine by antagonistic effects at the N-methyl-D-aspartate (NMDA) receptor by increasing the release and blocking the reuptake of dopamine. Initially, amantadine was approved as an antiviral drug before the serendipitously realized central nervous system effects. It is a prophylactic agent targeting M2 (AM2) viroprotein channel of influenza A virus [4]. Recently, it is hypothesized that amantadine may prevent the release of the viral nucleus into the cell cytoplasm blocking the viroporine channel of COVID-19 [5]. A high throughput drug screen gene expression analysis study proposed that amantadine disrupts the lysosomal gene expression [6]. Adamantane derivative drugs, including amantadine, suggested consideration in SARS-CoV-2 treatment that originates from its coronavirus efficiency [7].

\footnotetext{
*Address correspondence to this author at the Department of Neurology, Faculty of Medicine, Maltepe University, P.O. 34844 İstanbul, Turkey; Tel: +90-0850-8110251; E-mail: sevki.sahin@maltepe.edu.tr
}

Previous studies showed that SARS-CoV has been found partially responsible for the acute respiratory failure via trans-synaptic spread from nasopharynx through medulla oblongata which is the main center of respiration [8]. Thus, some encephalopathy cases related to SARS-CoV-2, which showed some similar brain involvement patterns with influenza and herpes viruses have been described, recently [9].

Amantadine also has clinical use to enhance arousal and cognition after traumatic brain injury by neurostimulation effect [10]. Amantadine may also improve decreased vigilance in 'post-comatose states' caused by different etiologies. We further hypothesize that if amantadine might be considered not only as an antiviral but also for its immunological and neurostimulant effects, it might be useful in the supportive treatment of SARS-CoV-2 cases, especially those patients who developed acute respiratory failure with decreased vigilance and monitored in the intensive care unit.

In accordance with our hypothesis, a case report with amantadine use suggested its protective role in COVID-19 [11]. However, clinical evidence, including phase III drug trials, is needed. Adverse drug reactions including cardiovascular, central nervous system and gastrointestinal system are well known in labeled indications, which should be monitored for safety concern. End stage renal failure is a contradiction and might be a limitation in its use in a subgroup of COVID-19 patients [10].

\section{CONSENT FOR PUBLICATION}

Not applicable.

\section{FUNDING}

None. 


\section{CONFLICT OF INTEREST}

The authors declare no conflict of interest, financial or otherwise.

\section{ACKNOWLEDGEMENTS}

All individuals listed as authors have contributed substantially to the drafting and revising the editorial.

\section{REFERENCES}

[1] Arreola R, Alvarez-Herrera S, Pérez-Sánchez G, et al. Immunomodulatory effects mediated by dopamine. J Immunol Res 2016; 20163160486

http://dx.doi.org/10.1155/2016/3160486 PMID: 27795960

[2] Levite M. Dopamine and T cells: dopamine receptors and potent effects on $\mathrm{T}$ cells, dopamine production in $\mathrm{T}$ cells, and abnormalities in the dopaminergic system in T cells in autoimmune, neurological and psychiatric diseases. Acta Physiol (Oxf) 2016; 216(1): 42-89.

http://dx.doi.org/10.1111/apha.12476 PMID: 25728499

[3] Kestenbaum M, Abu Snineh M, Nussbaum T, et al. Repeated Intravenous Amantadine Infusions in Advanced Parkinsonism: Experience of a Large Movement Disorder Center. Isr Med Assoc J 2019; 12(21): 812-6.

PMID: 31814345

[4] Cady SD, Luo W, Hu F, Hong M. Structure and function of the influenza A M2 proton channel. Biochemistry 2009; 48(31): 735664. http://dx.doi.org/10.1021/bi9008837 PMID: 19601584

[5] Aranda Abreu GE, Hernández Aguilar ME, Herrera Covarrubias D, Rojas Durán F. Amantadine as a drug to mitigate the effects of COVID-19. Med Hypotheses 2020; 140109755 [published online ahead of print, 2020 Apr 25].

http://dx.doi.org/10.1016/j.mehy.2020.109755 PMID: 32361100

[6] Sandra P Smieszek, Bart P Przychodzen, Mihael H. Polymeropoulos Amantadine disrupts lysosomal gene expression; potential therapy for COVID19. bioRxiv 2020; 04(05): 026187.

[7] Cimolai N. Potentially repurposing adamantanes for COVID-19. J Med Virol 2020; 92(6): 531-2.

http://dx.doi.org/10.1002/jmv.25752 PMID: 32176361

[8] Li YC, Bai WZ, Hashikawa T. The neuroinvasive potential of SARS-CoV2 may be at least partially responsible for the respiratory failure of COVID-19 patients. J Med Virol 2020; $\cdots$

http://dx.doi.org/10.1002/jmv.25728 PMID: 32104915

[9] Poyiadji N, Shahin G, Noujaim D, Stone M, Patel S, Griffith B. COVID-19-associated Acute Hemorrhagic Necrotizing Encephalopathy: CT and MRI Features. Radiology 2020, 201187201187

http://dx.doi.org/10.1148/radiol.2020201187 PMID: 32228363

[10] Amantadine: Drug information 2020 [April 6, 2020]; $\mathrm{https}: / /$ www.uptodate.com/contents/amantadine-druginformation

[11] Cortés Borra A. Does amantadine have a protective effect against COVID-19?J Neurol Neurochir Pol. 2020. http://dx.doi.org/10.5603/PJNNS.a2020.0041.

DISCLAIMER: The above article has been published in Epub (ahead of print) on the basis of the materials provided by the author. The Editorial Department reserves the right to make minor modifications for further improvement of the manuscript. 